Mark H. Zornow, MD, Thomas C. Thomas, MD, Mark S. Scheller, MD

\title{
The efficacy of three different methods of transtracheal ventilation
}

The ability of three different techniques of transtracheal ventilation to reverse hypoxia and provide pulmonary ventila. tion were examined. Five swine were anaesthetized with isoflurane in oxygen, their tracheas were intubated, and their lungs mechanically ventilated to produce a $\mathrm{PaCO}_{2}$ of $35-40$ $\mathrm{mmHg}$. A 14-gauge catheter was inserted percutaneously into the trachea caudad to the tip of the tracheal tube. The animals were then lefi apnoeic until their oxygen saturation fell to 60 per cent. At this point, attempts were made to ventilate and oxygenate the animals through the tracheal catheter with one of three systems (Jet - 50 psi [2585 $\mathrm{mmHg}$ ] driving pressure controlled with a thumb operated valve, Flush - fresh gas outlet of an anaesthetic machine with flow controlled by the flush button, or Circle - standard anaesthesia circle system with pressures greater than $60 \mathrm{mmHg}$ ). Arterial blood gas determinations were made every minute for five minutes afier beginning transtracheal ventilation. Both the Jet and Flush modes resulted in a mean $\mathrm{PaO}_{2}$ greater than $250 \mathrm{mmHg}$ within one minute of their initiation whereas the $\mathrm{PaO}_{2}$ with the Circle system never exceeded $180 \mathrm{mmHg}$ even at five minutes. The Flush and Jet modes produced a decrease in the $\mathrm{PaCO}_{2}$ (from $80 \mathrm{mmHg}$ to $35-45 \mathrm{mmHg}$ ) over the five minutes. In contrast, it was not possible to provide adequate ventilation with the Circle system

\section{Key words:}

VENTILATION; transtracheal, hypercarbia; HYPOXIA; CARBON DIOXIDE; elimination, hypercarbia; ANAESTHETIC TECHNIQUES; ventilation

From the Department of Anesthesiology, University of California at San Diego, San Diego, California.

Address all correspondence and reprint requests to:

Dr. M.H. Zornow, Neuroanesthesia Research, M-029, University of California at San Diego, La Jolla, CA 92093, Telephone (619) 534-3865.

Supported in part by a grant from the Ohmeda Corporation. The authors wish to thank Marjorie R. Grafe, M.D., Ph.D. for her assistance.

An abstract of this study was presented at the 1988 annual meeting of the Canadian Anaesthetists' Society. as evidenced by an increasing $\mathrm{PaCO}_{2}$ (from $80 \mathrm{mmHg}$ to $>110$ $\mathrm{mmHg}_{\mathrm{g}}$ at five minutes). This study suggests that pre-existing hypoxia can be reversed by the administration of oxygen via a tracheal catheter connected to an anaesthesia circuit. Ventilation, however, can be achieved only if the tracheal catheter is connected to a high pressure source of oxygen.

The inability to ventilate the lungs of a patient constitutes a true medical emergency. This unfortunate circumstance may occur in the operating room following induction of anaesthesia and will result in hypoxic brain injury and cardiac arrest if not promptly remedied. Transtracheal Ventilation (TTV) has been proposed as a possible life-saving technique when conventional manoeuvres to establish ventilation have failed. Transtracheal ventilation involves the percutaneous placement of a catheter into the tracheal lumen. A source of oxygen is then connected to the catheter and ventilation is accomplished by inflating the lungs via the tracheal catheter and allowing passive exhalation to occur through the mouth and nose. In the majority of patients whose lungs cannot be ventilated with a bag and mask, the primary obstruction is to the inflow of oxygen whereas exhalation remains relatively unimpeded. This view is supported by our clinical experience with TTV and numerous reports in the literature. As far back as 1956, Jacoby et al. reported five patients with large upper airway tumours who developed complete inspiratory obstruction following the induction of anaesthesia. Insufflation of oxygen through a tracheal catheter promptly restored oxygen saturation. The authors go on to note, "In each of these instances the patient was attempting to breathe but was unable to do so because of the mechanical obstruction by tumour tissue. Retraction of the intercostal spaces and of the soft tissues of the neck was obvious. When the flow of oxygen through the transtracheal needle was begun, the patient's efforts to breathe continued. No outside air entered the patient's trachea during the inspiratory phase. During exhalation, however, the release of gas was readily noticeable to the observer - both by sound and by feeling the gas blow against his hand."1 DeLisser et al. found that in patients in 
whom no other means of ventilation was possible, "When the oxygen flush valve is released, exhalation occurs passively during the interval between oxygen injections. This is possible because the obstruction in the upper airway is most likely due to a valve-like effect and not a total obstruction."2 Weymuller et al. comment that, "Even with a massive laryngeal tumor complicated by superimposed infection and associated with total inspiratory obstruction, there was adequate expiratory flow. This is explained by the 'ball-valve' effect of most laryngeal masses and the negative pressure generated by inspiratory effort, as contrasted to the positive pressure exerted by insufflation of oxygen under pressure distal to the incomplete obstruction."

There have been numerous techniques described in the literature for connecting the tracheal catheter to a source of oxygen. ${ }^{2,4-12}$ However, few investigations have carefully examined the ability of these systems to provide adequate ventilation and none has compared the efficacy of these various methods at reversing pre-existing hypoxia. We therefore examined three different systems of providing TTV in terms of their abilities to oxygenate and ventilate an animal model of upper airway obstruction.

\section{Methods}

The three methods of TTV examined in this study were: (1) Jet - the tracheal catheter (see below) was connected to the hospital piped oxygen supply (50 psi) via highpressure tubing with flow regulated by a thumb-operated value. ${ }^{13}$ This valve was activated at a rate of $15 \cdot \mathrm{min}^{-1}$ with an inspiratory/expiratory $(\mathrm{V} / \mathrm{E})$ ratio of approximately 0.25; (2) Flush - the tracheal catheter was connected to the fresh gas outlet on the anaesthesia machine via a length of high-pressure tubing. The oxygen flush button was depressed at a rate of $15 \cdot \mathrm{min}^{-1}$ with an $\mathrm{V} / \mathrm{E}$ ratio of approximately 0.25 . The oxygen supply for the anaesthesia machine was identical to that used for the Jet system (50 psi); (3) Circle - the tracheal catheter was connected to a standard anaesthesia circuit via a $3 \mathrm{~mm}$ endotracheal tube connector and vigorous attempts made at manual ventilation at a rate $>50 \cdot \mathrm{min}^{-1}$ and peak circle pressures consistently greater than $60 \mathrm{mmHg}$.

After obtaining institutional animal care committee approval, five healthy pigs (approximately $22 \mathrm{~kg}$ ) were sedated with IM ketamine $\left(20 \mathrm{mg} \cdot \mathrm{kg}^{-1}\right)$ and allowed to breathe 3.5 per cent isoflurane spontaneously. Following oral tracheal intubation, the lungs were ventilated in the supine position with 2-3 per cent isoflurane in oxygen to achieve a normal end-tidal $\mathrm{CO}_{2}$. Pancuronium $(0.2 \mathrm{mg}$. $\mathrm{kg}^{-1}$ ) was intermittently injected via an ear vein catheter to ensure muscle paralysis. Oxygen saturation was measured with a pulse oximeter probe (Nelcor Inc., Hayward, CA; model N25) placed on the animal's ear. Following infiltration with 0.25 per cent bupivacaine, a groin incision was made for the insertion of a femoral artery catheter for continuous monitoring of blood pressure and intermittent sampling of arterial blood for blood gas determinations (ABG). A two-inch, 14-gauge, IV catheter (Abbocath, Abbott Hospitals, Inc., North Chicago, IL) was then inserted percutaneously into the trachea caudad to the tip of the tracheal tube. Correct positioning in the tracheal lumen was verified by aspirating air through the catheter with a syringe and demonstrating the presence of $\mathrm{CO}_{2}$ on a capnometer which was connected to the catheter.

Following the surgical preparation, a stabilization period ensued to ensure that the $\mathrm{PaCO}_{2}$ was in the normal range (35-40 mm $\mathrm{mg}$ ) and that $\mathrm{PaO}_{2}$ was greater than 350 $\mathrm{mmHg}$, as demonstrated by two separate $\mathrm{ABG}$ determinations at least five minutes apart (B1 and B2, See Figures 1 and 2). At this time the $\mathrm{O}_{2}$ saturation was 100 per cent in all cases. The tracheal tube was then disconnected from the ventilator and a one-way valve was attached to the end of the tube which allowed for unrestricted exhalation but prevented the entrainment of room air. Exhaled volumes were measured by placing a Wright respirometer between the tracheal tube and the one-way valve. The animals were left apnoeic until their oxygen saturation fell to 60 per cent $(t=0)$ at which time ventilation was immediately begun with one of the three methods of TTV (Jet, Flush or Circle) selected at random. Arterial blood gas samples were drawn at $t=0$ (prior to commencing TTV) and at one minute intervals thereafter for the remainder of the ventilation period (five minutes). Expired volumes were recorded as each $A B G$ sample was drawn. After five minutes of TTV, conventional ventilation via the tracheal tube was resumed and the sequence was repeated using one of the other modes of TTV (each animal was ventilated with all three modes of ventilation). Upon completion of the experiment, the animals were killed with an IV bolus of $\mathrm{KCl}$ while still under general anaesthesia and the tracheas were removed and examined for proper placement of the catheter and evidence of injury to the trachea. Data were obtained from five animals and the mean values $( \pm S D)$ for $\mathrm{PaO}_{2}$ and $\mathrm{PaCO}_{2}$ at each sample time were calculated. The $\mathrm{PaO}_{2}$ and $\mathrm{PaCO}_{2}$ for each mode of ventilation were compared using a repeated measures ANOVA followed by Scheffe's test for multiple comparisons. Mean ( $\pm \mathrm{SD}$ ) volumes of gas exhaled per minute for each mode of TTV were calculated. Determinations of the maximum flow rate in $\mathrm{L} \cdot \mathrm{min}^{-1}$ through the 14-gauge catheter were made for each system of TTV using a collecting bag and a Wright respirometer.

\section{Results}

All animals were haemodynamically stable throughout 


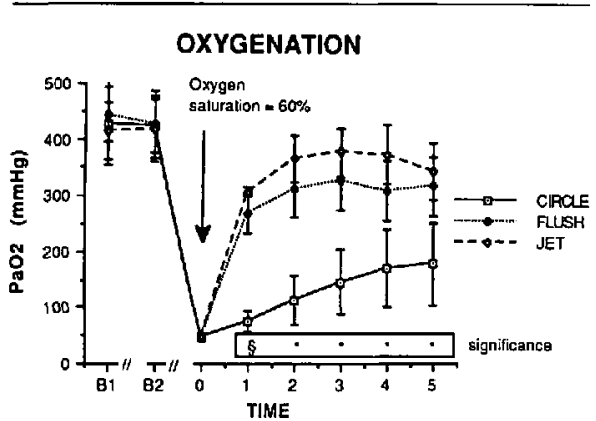

FIGURE 1. Arterial $\mathrm{PaO}_{2}$ with each of the three modes of TTV. (B) $=$ baseline $1, \mathrm{B2}=$ baseline 2) Significance $-\$=$ Jet $>$ Flush $>$

Circle, $P<0.05 ; *=$ Jet $>$ Circle and Flush $>$ Circle, $P<0.05$. No significant difference between Jet and Flush modes.

the course of the experiment. Prior to the start of each trial of TTV, the mean $\mathrm{PaCO}_{2}$ was $38.2 \pm 2.8 \mathrm{mmHg}$ with a $\mathrm{PaO}_{2}$ of $423.6 \pm 52.4 \mathrm{mmHg}$ (B2, see Figures 1 and 2). There were no differences in $\mathrm{PaCO}_{2}$ or $\mathrm{PaO}_{2}$ between the various groups at this point. After the animals bad been left apnoeic and their oxygen saturation had fallen to 60 per cent ( $t=0$, Figures 1 and 2 ) there were again no significant differences in $\mathrm{PaCO}_{2}(82.2 \pm 8.5 \mathrm{mmHg})$ or $\mathrm{PaO}_{2}(47.9 \pm 4.7 \mathrm{mmHg})$ prior to the application of any of the three methods of TTV. Figure 1 demonstrates that the $\mathrm{PaO}_{2}$ increased with all three modes of TTV. At $\mathrm{t}=$ one minute, the mean $\mathrm{PaO}_{2}$ was significantly different for all inter-group comparisons (i.e. Jet $>$ Flush $>$ Circle, $P<0.05$ ). At each subsequent time point, the mean $\mathrm{PaO}_{2}$ in the Jet and Flush groups was greater than the mean $\mathrm{PaO}_{2}$ in the Circle group, but no differences existed between the Jet and Flush modes.

Figure 2 demonstrates that both the Jet and Flush modes resulted in decreasing mean $\mathrm{PaCO}_{2}$ values when compared with $t=0$. At $t=$ three and $t=$ four minutes the Jet $\mathrm{PaCO}_{2}$ was less than that of the Flush $\mathrm{PaCO}_{2}$. Attempts at providing TTV with the Cirele mode resulted in an increasing $\mathrm{PaCO}_{2}$ at all points beyond $\mathrm{t}=0(\mathrm{P}<$ 0.05 Circle vs Flush and $P<0.05$ Circle vs Jet modes).

Gross inspection of the tracheas demonstrated proper positioning of all TTV catheters. Microscopic examination revealed full-thickness erosion and haemorrhage of the posterior tracheal mucosa in all animals near the tip of the tracheal catheter (Figure 3). These lesions were uniform in size and shape $(\approx 0.8 \times 1.2 \mathrm{~cm}$ in diameter $)$.

Maximum flow rates as measured by timed collections through the 14-gauge catheter for Circle, Flush, and Jet modes were 9,45 , and $57 \mathrm{~L} \cdot \mathrm{min}^{-1}$ respectively. Exhaled gas flow rates through the endotracheal tube during TTV

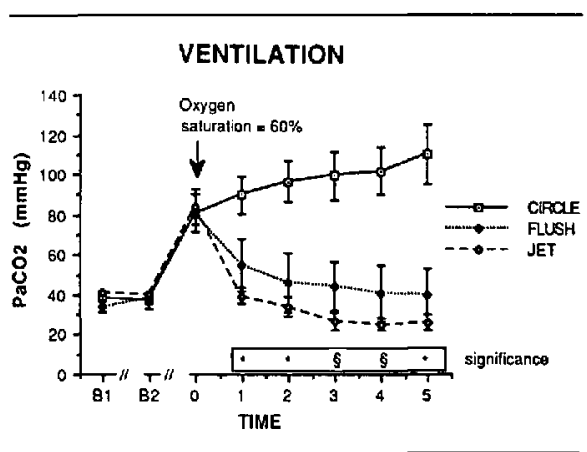

FIGURE 2. Arterial $\mathrm{PaCO}_{2}$ with each of the three modes of TTV. (BI = baseline 1, B2 = baseline 2) Significance $-\S=$ Jet $>$ Flush $>$

Circle, $P<0.05 ;^{*}=$ Jet $<$ Circle and Flush $<$ Circle, $P<0.05$ No significant difference between Jet and Flush modes.

as measured by the Wright respirometer were $0 \mathrm{~L} \cdot \mathrm{min}^{-1}$ (Circle), $7.88 \pm 2.49 \mathrm{~L} \cdot \mathrm{min}^{-1}$ (Flush), and $10.54 \pm$ $0.94 \mathrm{~L} \cdot \mathrm{min}^{-1}(\mathrm{Jet})$

\section{Discussion}

The inability to ventilate the lungs and oxygenate a patient with airway obstruction will result in serious hypoxia and hypercarbia within a matter of minutes. In the rare patient for whom conventional techniques of airway management fail to relieve the obstruction, prompt institution of TTV may prove to be a lifesaving manoeuvre.

Although numerous articles have been written describing various techniques for connecting a tracheal catheter to a source of oxygen, few of these studies have examined the effect of these proposed systems on the $\mathrm{PaCO}_{2}$ or $\mathrm{PaO}_{2}$ and none has examined their relative ability to reverse pre-existing hypoxia and hypercarbia. We therefore studied the effects of three different methods of providing TTV in what we feel is an accurate animal model of airway obstruction such as may occur in the operating or emergency room. In this model, stable and similar baseline ABGs were obtained prior to the initiation of TTV. The use of a pulse oximeter allowed us to have constant real-time monitoring of the desaturation which occurred during the ensuing period of apnoea. We were therefore able to institute TTV at the same degree of hypoxaemia in all animals. A one-way valve was attached to the tracheal tube which allowed unrestricted exhalation while preventing entrainment of room air. This was to simulate the common clinical situation where it is difficult or impossible to force oxygen under positive pressure into the lungs but egress of gas is relatively unimpeded. By leaving the tracheal tube in place during TTV, possible variations in the degree of airway obstruction during 


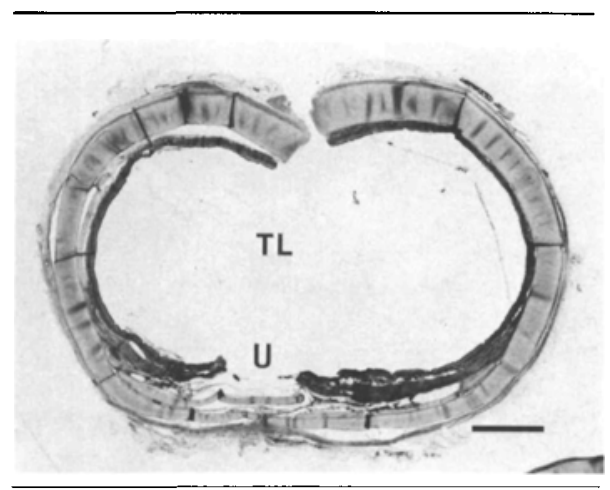

FIGURE 3. Photomicrograph of horizontal section of trachea following TTV. TL = tracheal lumen. $U=$ trans-mucosal ulceration of posterior tracheal wall. Bar $=2 \mathrm{~mm}$. The anterior tracheal wall had been incised prior to fixation and sectioning.

exhalation were eliminated. The use of a Wright respirometer permitted us to estimate the ventilation that resulted from each of the three modes of TTV. Although consideration was given to measuring intra-tracheal pressures, these values would vary depending on the relative positions of the ventilating and monitoring catheters (positive pressures in the distal airways, negative pressures in the larynx and proximal trachea due to a Venturi effect). Furthermore, since such data would be unavailable in the clinical situation, we elected to standardize $\mathrm{V} / \mathrm{E}$ ratio and respiratory rate for the Flush and Jet systems.

Our results demonstrate that a high-pressure source of oxygen is needed during TTV to provide adequate ventilation and reverse pre-existing hypoxia quickly in this animal model of airway obstruction. We used a $50 \mathrm{psi}$ source of oxygen for both the Flush and Jet systems. Lower (15-30 psi) sources have been successfully utilized in humans and may minimize the tracheal injury we observed in these experiments. ${ }^{14}$

Although it is well known that apnoeic oxygenation can maintain arterial oxygen saturation for a prolonged period of time, we were able to demonstrate that the tracheal administration of oxygen at a low flow rate could reliably reverse pre-existing hypoxaemia. While insufflation of oxygen through a tracheal catheter using the anaesthesia Circle system did eventually reverse the hypoxia, the rise in the $\mathrm{PaO}_{2}$ was much slower than that achieved with either the Flush or Jet systems. Furthermore, the final value for the $\mathrm{PaO}_{2}$ produced by the Circle system even after five minutes of insufflation was $140 \mathrm{mmHg}$ lower than that produced by the Flush or Jet systems. Although the $\mathrm{PaO}_{2}$ produced by the Circle system may seem adequate, it should be remembered that these values were obtained in animals with normal lungs. In a patient with pre-existing pulmonary disease, much lower values may be obtained.

The $\mathrm{PaCO}_{2}$ values clearly demonstrate the inability of the Circle system to provide adequate ventilation. The $\mathrm{PaCO}_{2}$ continually increased over the five-minute period of TTV using the Circle system whereas it decreased to near normal levels within two to three minutes of initiation of TTV with either the Flush or Jet systems. Since we limited ventilation with the Flush and Jet methods to 15 breaths $\cdot \min ^{-1}$ while making maximal efforts to ventilate with the Circle system, the difference between these techniques in terms of their ability to ventilate may be even greater than the values which we report in this study. The trend towards lower $\mathrm{PaCO}_{2}$ values that were seen with the Jet system may have been due to the higher maximum flow rates that could be achieved with this device. This is reflected in the greater exhaled volumes $\left(10.54 \mathrm{~L} \cdot \mathrm{min}^{-1}\right)$ in the Jet group compared with the Flush group $\left(7.88 \mathrm{~L} \cdot \mathrm{min}^{-1}\right)$ despite identical respiratory rates. The fact that no exhaled volumes could be recorded in the Circle group may have been due to the inability of the Wright respirometer to detect the low flows produced by this method (especially since some of the insufflated oxygen had diffused across the alveolar membrane). Oxygen supply pressures for both the Jet and Flush systems were 50 psi. We speculate that the lower flow rates, smaller exhaled volumes, and higher $\mathrm{PaCO}_{2}$ values in the Flush group were due to a relative resistance in the anaesthesia machine (Narcovet, North American Drager Inc.) to the high gas flow rates employed in this study. The flush system used on the machine employed in this study is identical to that found on the anaesthesia machines used in clinical practice.

Although TTV with a high pressure source of oxygen may prove to be a lifesaving technique, the tracheal ulcerations that we found in all animals emphasize that this is not an entirely benign procedure. Numerous complications have been reported following attempts at TTV including haemorrhage, subcutaneous and/or mediastinal emphysema, oesophageal injury, air embolization, barotrauma resulting in pneumothorax, and fire during use of electrocautery. ${ }^{\text {is }}$ In those instances where exhalation cannot easily occur, there is the potential for the development of high intrathoracic pressure which may compromise venous return to the heart and cardiac output. In addition, it must be remembered that with TTV the airway is not secured and aspiration may occur. Despite these limitations and complications, in the patient whose lungs cannot be ventilated with conventional means, TTV may be rapidly instituted and prove to be a lifesaving alternative to tracheostomy or cricothyrotomy. 


\section{References}

1 Jacoby JJ, Hamelberg, W, Ziegler $\mathrm{CH}$, et al. Transtracheal resuscitation. JAMA 1956; 162: 625-8.

2 DeLisser EA, Muravchick S. Emergency transtracheal ventilation. Anesthesiology 1981; 55: 606-7.

3 Weymuller EA, Pavlin EG, Paugh D, Cummings, $C W$. Management of difficult airway problems with percutaneous transtracheal ventilation. Ann Otol Rhinol Laryngol 1987; 96: 34-7.

4 Reich $D L$, Schwartz N. An easily assembled device for transtracheal oxygenation. Anesthesiology 1987; 66: 437-8.

5 Stinson $T W$. A simple connector for transtracheal ventilation. Anesthesiology 1977; 47: 232.

6 Scuderi PE, McLeskey CH, Comer PB. Emergency percutaneous transtracheal ventilation during anesthesia using readily available equipment. Anesth Analg 1982; 61: 867-70.

7 Dunlap LB. A modified, simple device for the emergency administration of percutaneous transtracheal ventilation JACEP 1978; 7: 42-6.

$8 \mathrm{Jacobs} H B$ : Emergency percutaneous transtracheal catheter and ventilator. J Trauma $1972 ; 12: 50-5$.

9 Spoerel WE, Narayanan PS, Singh NP. Transtracheal ventilation. Br J Anaesth 1971; 43: 932-9.

10 Smith RB, Babinski M, Klain M, Pfaeffle H. Percutaneous transtracheal ventilation. JACEP 1976; 5: 765-70.

11 Attia RR, Battit GE, Murphy JD. Transtracheal ventilation. JAMA 1975; 234: 1152-3.

12 Fisher JA. A "last ditch" airway. Can Anaesth Soc J 1979; 26: $225-30$.

13 Millar WL. Management of a difficult airway in obstetrics. Anesthesiology 1980; 52: 523-4.

14 Lawler RA, Chang JL. Dudman A, Rubiano R. Nonflammable endotracheal device for $\mathrm{CO}_{2}$ laser ablation of benign laryngeal and proximal tracheal tumors. Laryngoscope 1986; 96: 1378-80.

15 Bowdle TA, Glenn M, Colston $H$, Eisele D. Fire following use of electrocautery during emergency percutaneous transtracheal ventilation. Anesthesiology 1987; 66: 697-8.
Résumé

Pour évaluer la performance de trois modes de ventilation transtrachéale, nous avons placé un cathéter percutané de calibre 14 au delà de l' extrémité distale du nube endotrachéal de cinq cochons préalablement ventilés avec axygène et isoflurane $\left(\mathrm{PaCO}_{2} 35-40 \mathrm{mmHg}\right)$, Quand la saturation en oxygene des cochons laissés en apnée atteignait 60 pour cent, nous tentions de les ventiler et de les oxygéner avec le cathéter transtrachéal en utilisant soit le mode Jet avec une valve à haute pression $(50$ psi ou $2585 \mathrm{~mm} \mathrm{Hg}$ ) contrólée au pouce, soit le mode Flush avec branchement à l'orifice de sortie de l'appareil d'anesthésie et controle par le dispositif a gros débit d'oxygène, soit le mode Circle ou on générait des pressions de plus de $60 \mathrm{mmH} g$ dans un circuit fermé standard. Des lors, nous mesurians les gaz artériels cinq fois à intervalle d' une minute. Après une minute en Jet ou en Flush, la $\mathrm{PaO}_{2}$ s'élevait à plus de $250 \mathrm{mmHg}$ tandis qu'en Circle, elle ne dépassait pas $180 \mathrm{mmHg}$, même d̀ cinq minutes. Par ailleurs, en Jet et en Flush, la $\mathrm{PaCO}_{2}$ passait de 80 a 35-45 $\mathrm{mmH}$ g en cinq minutes alors qu' elle augmentait de 80 d plus de $110 \mathrm{mmHg}$ après cinq minutes en Circle. II semble donc qu'on peut corriger l'hypoxie en donnant de l'oxygène via un cathéter transtrachéal branché sur un circuit anesthésique ordinaire cependant, une ventilation adéquate requiert la connexion de ce catheter sur une source d'oxygène d haute pression. 